\title{
Ligamentum Flavum Buckling Causing Immediate Post-Operative Neurological Deterioration After an Anterior Cervical Discectomy: Case Report
}

\author{
Mohammad TAGHVAEI ${ }^{1,2}$, Keyvan Tayebi MEYBODI ${ }^{1,2}$, Mehdi ZEINALIZADEH ${ }^{1,2}$ \\ ${ }^{1}$ Tehran University of Medical Sciences, Imam Khomeini Hospital, Department of Neurological Surgery, Tehran, Iran \\ ${ }^{2}$ Tehran University of Medical Sciences, Imam Khomeini Hospital, Brain and Spinal Injury Research Center (BASIR), Tehran, Iran
}

\section{ABSTRACT}

Neurological injury is a potential complication of anterior cervical discectomy (ACDF). latrogenic trauma, hypoxic-ischemic damage during surgery or epidural hematoma could cause neurological deterioration after surgery. This is the first case being reported of neurological deterioration after an anterior cervical discectomy due to ligamentum flavum buckling. The case illustrated an uncommon cause of cord compression after ACDF. Therefore, ligamentum flavum buckling should be considered as one of the potential causes for acute neurologic deterioration after an anterior cervical discectomy. While keeping this rare complication in mind, obtaining a quick post-operative imaging seems mandatory in early detection and establishing an appropriate management.

KEYWORDS: Anterior cervical discectomy, Anterior cervical fusion, Cervical spine, Ligamentum flavum, Spinal cord compression

\section{INTRODUCTION}

\begin{abstract}
$\Delta$ nterior cervical discectomy and fusion (ACDF) has become one of the most frequently performed surgical procedures for the management of symptomatic cervical disc herniation world-wide. Despite the quite satisfactory clinical outcome of this procedure in the majority of cases, the associated complications such as postoperative hematoma, recurrent laryngeal nerve paresis, dysphagia, dural tearing, esophageal laceration, worsening of myelopathy, and vascular injury can be troublesome or life-threatening (3).

To the best of our knowledge, ligamentum flavum buckling has not been reported to be a cause of postoperative neurologic deterioration and spinal cord compression in literature. In this case report, we describe a patient with C5/6 cervical disc herniation who developed neurological deterioration just after ACDF due to infolding of the ligamentum flavum and spinal cord compression.
\end{abstract}

\section{CASE REPORT}

A 48-year-old male taxi driver presented to our department with a 5-year history of neck pain and associated radicular pain and paresthesia in right upper limb. Since 20 days before admission, he had developed progressive weakness of all extremities and inability to walk. The preoperative neurological examination revealed spastic quadriparesis (motor power: 3/5), positive Hoffman's and Babinski's signs.

Magnetic resonance imaging (MRI) of the cervical spine revealed C5/6 disc extrusion with subligamentous upward disc migration, significant canal compromise, and spinal cord hyperintensity in T2-weighted images (Figure 1A, B). Computed tomography (CT) scan did not show any bony compression (Figure 1C).

After induction of general anesthesia and successful fiberoptic intubation, the patient was carefully positioned without any 
hyperextension. Microscopic C5/6 discectomy was performed in a standard manner. Sufficient spinal cord and bilateral nerve roots decompression under microscopic guidance were done and fusion was performed with inserting an intervertebral Polyether ether ketone (PEEK) Cage (Locking Cage cervical: HRCC $®$, EUROSPINE, France). A suction drain was left in the prevertebral space and the surgical wound was closed in anatomic layers. No inconvenient surgical or hemodynamic events occurred during surgery.

An immediate postoperative examination in the recovery unit revealed that the patient was unable to move his lower limbs and both distal parts of upper extremities.

An urgent MRI and CT scan were obtained and demonstrated posterior spinal cord compression because of infolding of the ligamentum flavum into the spinal canal at the level of discectomy. The PEEK cage was in its appropriate position (Figure 2A-D).
The patient underwent urgent posterior decompression with C4 to C6 laminectomies. Ventrally buckled ligamentum flavum that impinged on the thecal sac was seen. Infolded ligamentum was excised and the surgical wound was meticulously closed in anatomic layers. The patient showed rapid motor power improvement $(3 / 5)$ in upper and lower extremities bilaterally the day after the second surgery.

One month after surgery and undergoing simultaneous rehabilitation, he had gained considerable improvement in muscle strength and was able to walk without aid. Cervical spine MRI after one month demonstrated complete canal decompression (Figure 3).

\section{DISCUSSION}

Various ACDF-related complications have been previously reported in the literature. Although, the neurological complications associated with anterior cervical discectomy are
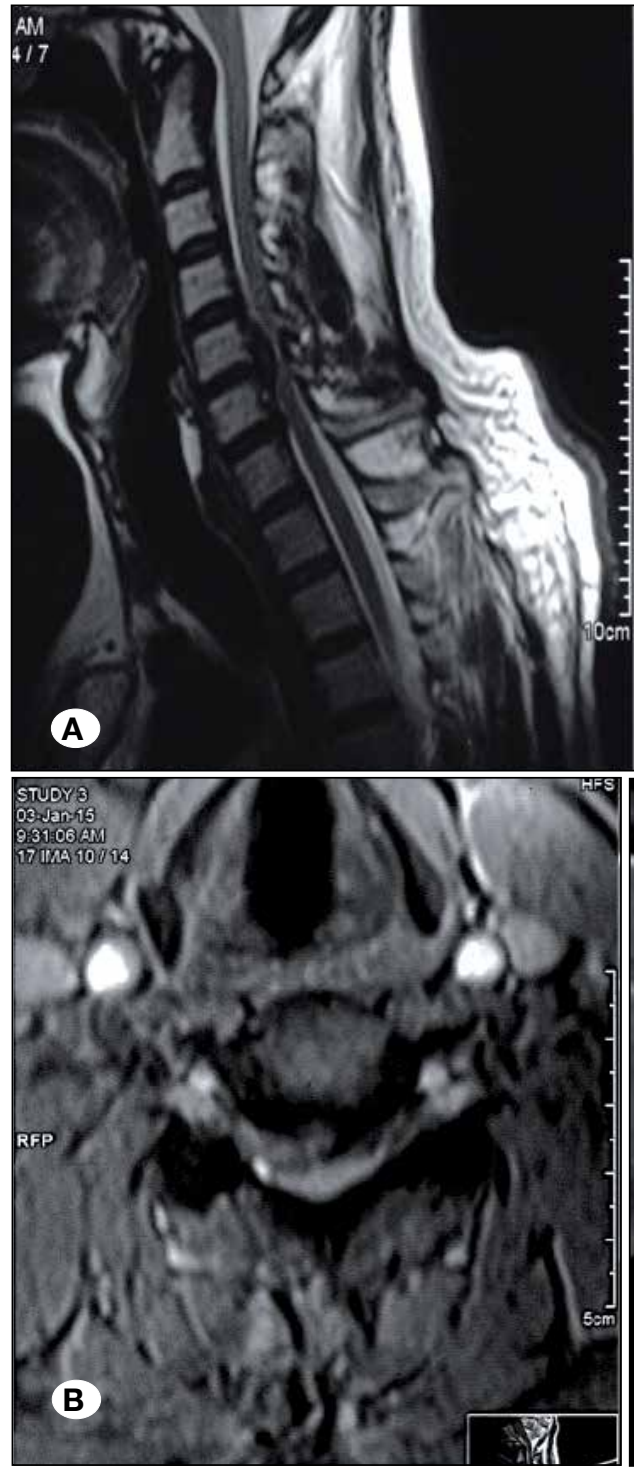
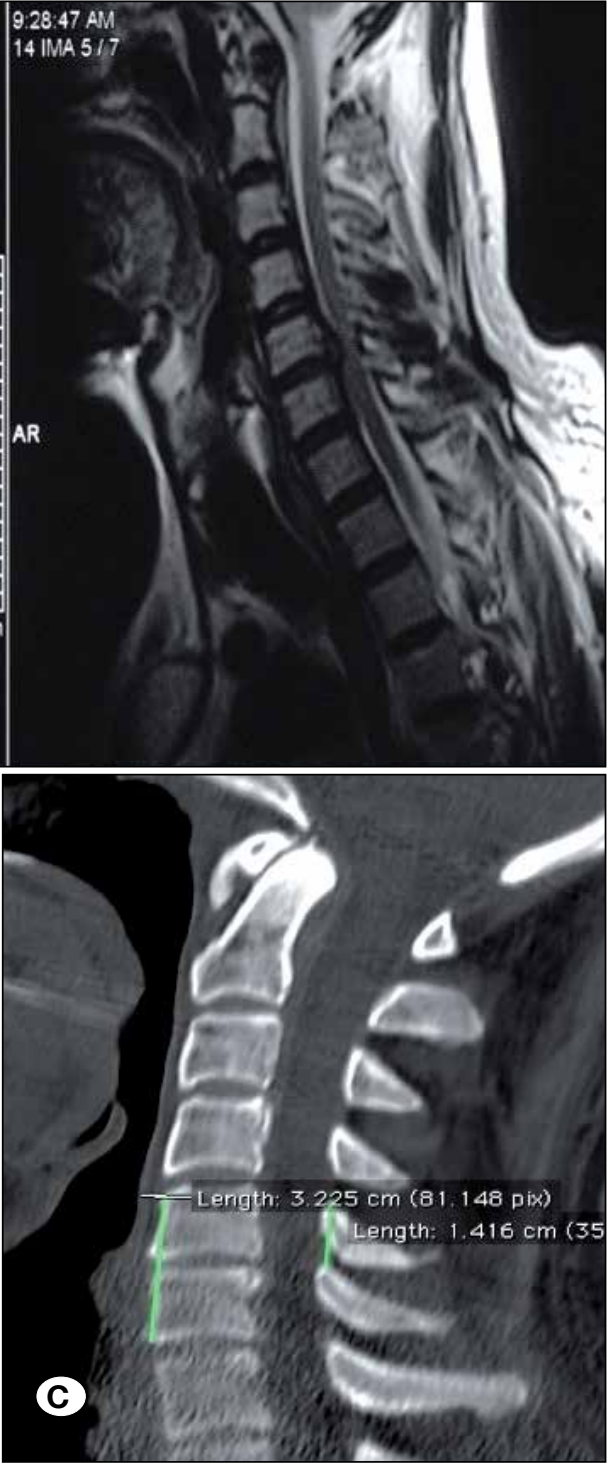

Figure 1: A) Preoperative sagittal T2 weighted MRI sections. There is C5/6 disc extrusion and subligamentous upward migration with significant canal compression. No evidence of ligamentum disruption is seen. B) Preoperative axial T1 weighted MRI. Foraminal stenosis secondary to disc herniation is evident. C) Preoperative midsagittal reconstructed CT scan image. 
generally considered to be rare, they are clearly not negligible and sometimes lead to significant morbidity and mortality (1, 3,5).

This paper documents the first report describing infolding of the ligamentum flavum as a cause of spinal cord compression and neurological deterioration after ACDF surgery. In spinal degenerative diseases because of ligamentum flavum protrusion into the spinal canal or foramens, radiculopathy, myelopathy or cauda equina signs and symptoms have been described (7).

Rhee et al. reported two neurological intact patients in whom neurological injury occurred due to infolding of the ligamentum flavum and spinal cord compression after reduction of cervical facet subluxations (8). In both the cases, the ligamentum flavum was torn and buckled during reduction; and patients improved neurologically with posterior decompression. However, no obvious radiological evidence of ligamentum flavum rupture or significant infolding was found in preoperative MRI scans in our patient.
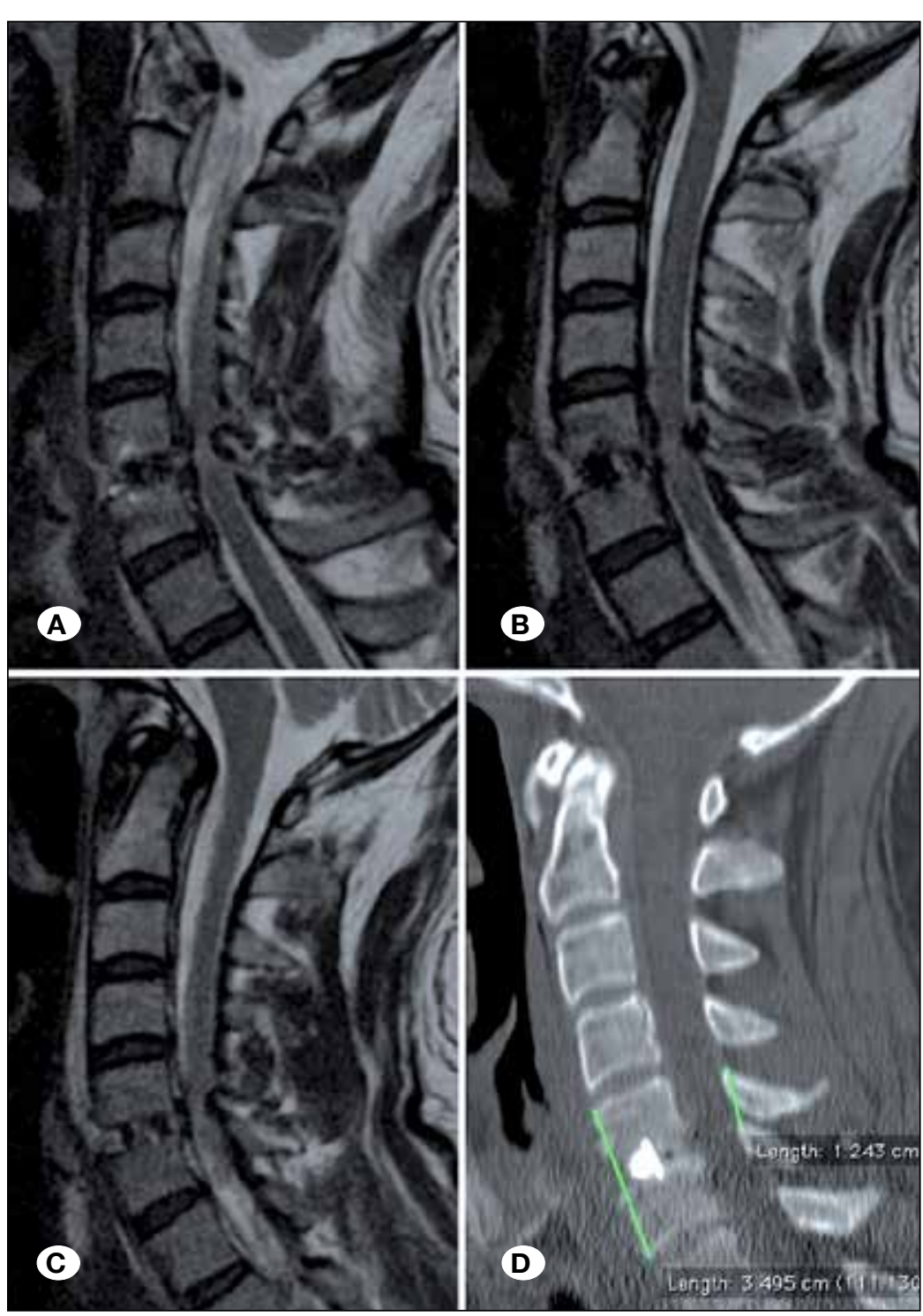

Figure 2: A-C) Just postoperative sagittal T2 weighted MRI. Note the spinal cord compression from posterior because of infolding of the ligamentum flavum into the spinal canal at the level of discectomy. D) Postoperative midsagittal reconstructed CT scan image revealed no evidence of cage displacement or bony compression. 


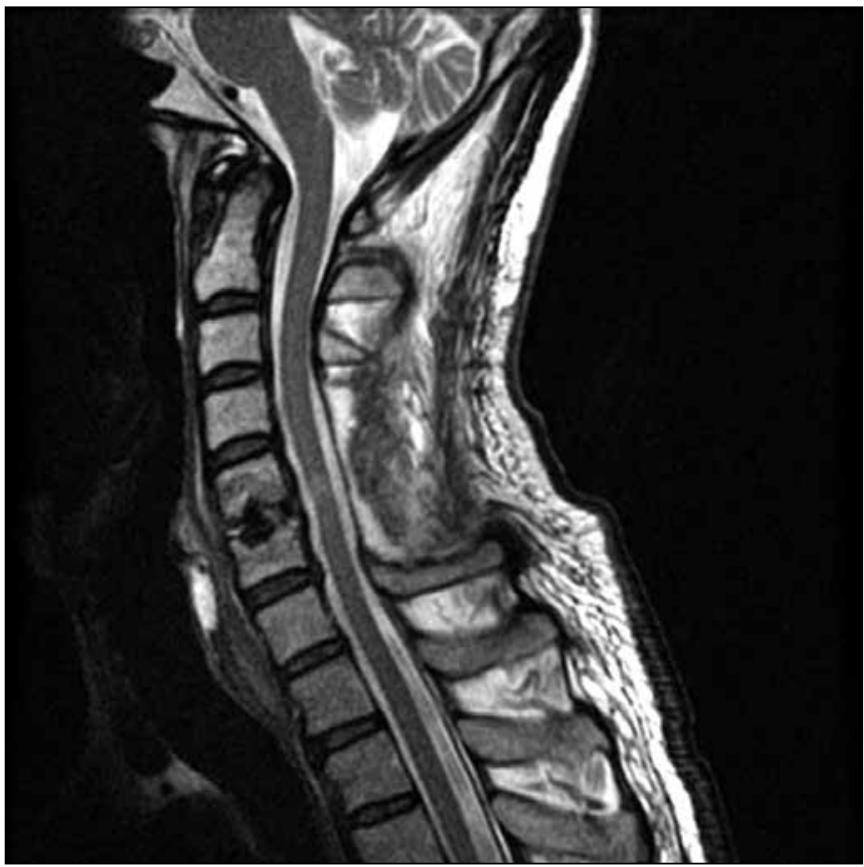

Figure 3: Cervical spine MRI one month after laminectomy demonstrated complete canal decompression. Lamina and ligamentum flavum have been resected at the levels of C4 to C6.

sociated with buckling of ligamentum flavum. In this case, the distance between anterior upper part of $\mathrm{C} 5$ vertebrae body and anterior lower part of $\mathrm{C} 6$ vertebrae body was increased (32.2 $\mathrm{mm}$ vs. $34.9 \mathrm{~mm}$ ) while C5/6 interspinous diameter was decreased postoperatively compared to pre-operative CT scan (12.4 mm vs. $14.2 \mathrm{~mm}$ ) (Figure 1C, Figure 2D). Therefore, choosing an appropriate size of the intervertebral cage based on pre -operative CT scan could avoid this complication.

Another pathology that could be responsible for acute quadriparesis in this scenario is flaval hematoma. Hematoma could be either spontaneous, traumatic, or due to bleeding tendencies $(6,9)$, but in this case no evidence of ligamentum flavum hematoma was found in postoperative MRI.

\section{CONCLUSION}

Although ACDF is a safe and effective procedure for symptomatic cervical disc herniation, the complications associated with this procedure should not be underestimated. Spinal cord compression due to infolding of the ligamentum flavum after anterior cervical discectomy has not been previously reported. The possibility of ligamentum buckling should be considered in patients with deterioration in neurological status after this procedure and a quick post-operative MRI should be performed. Furthermore, posterior decompression of the spinal cord could improve neurological deficits. So, the importance of early diagnosis and appropriate management is highly demanded.

\section{ACKNOWLEDGMENT}

The authors wish to thanks Dr. Zahid Hussain Khan for editing this manuscript.

\section{- REFERENCES}

1. Bertalanffy H, Eggert HR: Complications of anterior cervical discectomy without fusion in 450 consecutive patients. Acta Neurochir (Wien) 99:41-50, 1989

2. Chokshi FH, Quencer RM, Smoker WR: The "thickened" ligamentum flavum: Is it buckling or enlargement? AJNR Am J Neuroradiol 31:1813-1816, 2010

3. Fountas KN, Kapsalaki EZ, Nikolakakos LG, Smisson HF, Johnston KW, Grigorian AA, Lee GP, Robinson JS Jr: Anterior cervical discectomy and fusion associated complications. Spine (Phila Pa 1976) 32:2310-2317, 2007

4. Guppy KH, Hawk M, Chakrabarti I, Banerjee A: The use of flexion-extension magnetic resonance imaging for evaluating signal intensity changes of the cervical spinal cord. J Neurosurg Spine 10:366-373, 2009

5. Lied B, Sundseth J, Helseth E: Immediate (0-6 h), early (6$72 \mathrm{~h}$ ) and late (>72 h) complications after anterior cervical discectomy with fusion for cervical disc degeneration; discharge six hours after operation is feasible. Acta Neurochir (Wien) 150:111-118, 2008

6. Miyakoshi N, Shimada Y, Kasukawa Y, Ando S: Ligamentum flavum hematoma in the cervical spine - case report. Neurol Med Chir (Tokyo) 46: 556-558, 2006

7. Okuda T, Fujimoto Y, Tanaka N, Ishida O, Baba I, Ochi M: Morphological changes of the ligamentum flavum as a cause of nerve root compression. Eur Spine J 14: 277-286, 2005

8. Rhee JM, Kimmerly WS, Smucker JD: Infolding of the ligamentum flavum: A cause of spinal cord compression after reduction of cervical facet injuries. J Spinal Disord Tech 19: 208-212, 2006

9. Wild F, Tuettenberg J, Grau A, Weis J, Krauss JK: Ligamentum flavum hematomas of the cervical and thoracic spine. Clin Neurol Neurosurg 116: 24-27, 2014 